
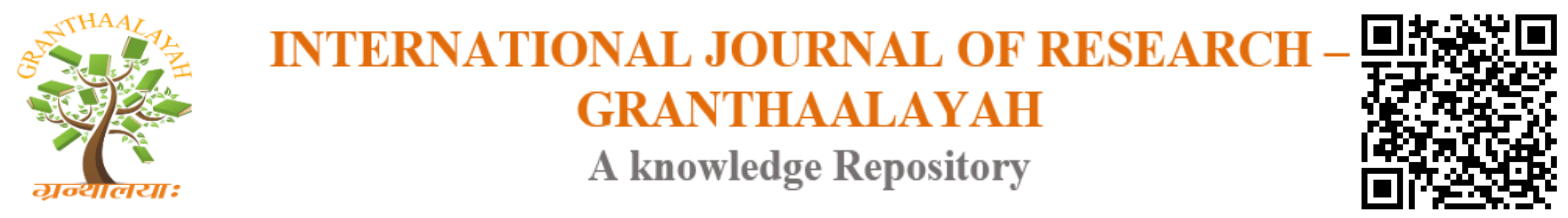

Science

\title{
MECHANICAL PROPERTIES OF DISCONNECTED MULTIWALLED CARBON NANOTUBES AND CARBON NANOTUBE COMPOSITES - A REVIEW PAPER
}

\author{
Elias Randjbaran *1, Rizal Zahari 1, 2, Dayang L. Majid 1, Mohamed T. H. Sultan 1, \\ Norkhairunnisa Mazlan ${ }^{1}$ \\ ${ }^{1}$ Aerospace Manufacturing Research Centre (AMRC) Level 7, Tower Block, Faculty of \\ Engineering 43400 UPM, Serdang, Selangor, Malaysia \\ ${ }^{2}$ Systems Engineering Department, Military Technological College, Muscat, Sultanate of Oman
}

\begin{abstract}
Motivation/Background: Current review paper is about the forecast of Young's modulus for carbon nanotubes, from both hypothetical and exploratory angles are introduced. The disparities between the estimations of Young's modulus announced in the writing are broke down, and distinctive patterns of the outcomes are examined. Explain the importance of the problem investigated in the paper. Include here a statement of the main research question.

Method: A whole investigation is performed to feature the obstructions and downsides of the demonstrating methods and crucial presumptions utilized which ought to be defeated in additionally contemplates.

Conclusions: The perspectives that ought to be considered all the more precisely in demonstrating carbon nanotube composites are distinguished.
\end{abstract}

Keywords: Carbon Nanotubes; Composites; Mechanical Properties; Imaging.

Cite This Article: Elias Randjbaran, Rizal Zahari, Dayang L. Majid, Mohamed T. H. Sultan, and Norkhairunnisa Mazlan. (2018). "MECHANICAL PROPERTIES OF DISCONNECTED MULTIWALLED CARBON NANOTUBES AND CARBON NANOTUBE COMPOSITES - A REVIEW PAPER.” International Journal of Research - Granthaalayah, 6(6), 212-225. https://doi.org/10.29121/granthaalayah.v6.i6.2018.1368.

\section{Introduction}

Carbon nanotubes (CNTs) are another age of materials having unrivalled mechanical, and electrical properties [1-3]. The exploratory estimation of their mechanical parameters is a monotonous errand. In this manner, the re-enactment and demonstrating procedures assume a noteworthy part in portraying their properties and in understanding their mechanical conduct. The uses of CNTs as strengthening specialists of polymer lattice composites are broad. Qian et al. [4] announced a 35 to $42 \%$ expansion in the versatile modulus and a $25 \%$ expansion in quality just by adding just $1 \mathrm{wt}$. percentage CNT to a polyester sap. The forecast of mechanical properties of 
CNTs is not just a single of the most essential issues which ought to be tended to sensibly, yet additionally the initial phase in portraying the mechanical properties of CNT/polymer composites. There is an imperative request of understanding the properties of CNT-strengthened polymers in their plan and examination as another age of composite materials. In addition, unique issues, for example, the interphase area between a CNT and its encompassing polymer, the pressure exchange from framework to a CNT, the introduction, and scattering of CNTs in a lattice, and the CNT waviness ought to be considered in the improvement of CNT composites. The fundamental objective of this paper is to audit the examinations on the mechanical properties of CNTs and CNT-based composites.

\section{Materials and Methods}

CNT and Its Structure a SWCNT can be schematically envisioned as a moved graphene sheet shaping an empty tube. The tube comprises of carbon hexagons and might be topped significantly a buck ball at every of it end. The structure of a CNT is characterized by its chiral vector and chiral edge [5]. The chirality of the tube affects its electronic properties [6]. The chiral vectors (n, 0 ) and (n, n) speak to "crisscross" (Z) and "rocker" (A) CNT designs, individually. Characterizing the touch of a tube, the chiral point shifts approximately 0 and $30^{\circ}$ [7]. Writing Survey of the Mechanical Properties of SWCNTs Numerous trial ponders have been performed to decide the mechanical properties of CNTs, however they indicate exceedingly extraordinary outcomes because of contrasts in the exploratory strategies utilized. As indicated by the estimation methods utilized, the test examinations can be separated into two noteworthy classes — "coordinate" and "aberrant" ones. The little measurements of CNTs and the situation of CNTs in a proper testing setup force a few challenges on exploratory examinations. Then again, the utilization of a coveted stacking and the estimation of disfigurements at nanometre length scales are different difficulties looked by researchers. The distinctive outcomes for the Young's modulus of SWCNTs acquired tentatively are appeared. The assorted variety in the trial esteems revealed can be credited to the accompanying principle reasons. Such as first, the absence of legitimate, direct estimating strategies at the nanometre scale; second, enormous impediments on the example estimate; third, vulnerability in the information acquired from circuitous estimations; fourth, deficiency in the readiness methods of test examples and the absence of control over the arrangement and dissemination of nanotubes. The to a great degree scattered information acquired through exploratory perceptions have urged numerous analysts to seek after an assortment of hypothetical examinations on the powerful properties of nanotubes so as to both legitimize the perception of test information and give required data, which isn't available utilizing trial strategies. A huge measure of research has been directed to remove and portray the mechanical properties of CNTs. The hypothetical and computational endeavours can be isolated into three primary classes:precious stone flexibility-based methodologies or atomistic displaying [14, 15], logical continuum mechanics-based methodologies [7], numerical continuum mechanics-based methodologies, alluded to as limited component strategies (FEMs) [16]. Hypothetically, the concoction data on materials can be found by explaining the Schrödinger wave condition for electrons of the framework considered, the places of iotas in which are basic information. The atomistic demonstrating predicts the places of molecules in view of intelligent powers and limit conditions [14]. The atomistic demonstrating methods can be grouped into three primary classifications, in particular the sub-atomic flow (MD), Monte Carlo (MC), and abdominal muscle initio approaches. While the MD techniques for the most part depend on deterministic conditions, the MC approach 
is stochastic; in any case, the primary part of MD and MC reproductions can be started in second Newton's law. In the interim, the systems are developed based on a precise arrangement of the Schrödinger condition. There are additionally some custom fitted and joined techniques, for example, the tight holding sub-atomic elements (TBMD), nearby thickness (LD), and thickness useful hypothesis (DFT) approaches, which require an outrageous measure of concentrated calculation [15]. In the MD and MC strategies, the powers following up on particles are gotten by separating interatomic potential capacities. An extensive number of interatomic potential models, running from easy to extremely entangled ones, can be found in the writing [7, 14]. The initio strategies are without potential techniques, in which the powers on particles are found from electronic structure computations as a dynamic undertaking.

This section should provide enough detail to allow full replication of the study by suitably skilled investigators. Protocols for new methods should be included, but well-established protocols may simply be referenced. We encourage authors to submit, as separate supporting information files, detailed protocols for newer or less well-established methods.

An important aspect of all scientific research is that it be repeatable. This gives validity to the conclusions. The materials and methods section of a manuscript allow other interested researchers to be able to conduct the experience to expand on what was learned and further develop the ideas. It is for this reason that this section of the paper be specific. It must include a step-by-step protocol along with detailed information about all reagents, devices, and subjects used for the study. How the data was constructed, collected, and interpreted should also be outlined in detail, including information on all statistical tests used.

\section{Results and Discussions}

Investigative continuum mechanics are kind of examination utilizes the continuum mechanics speculations of bars, brackets, pillars, shells, or bended plates. It is important to research precisely the level of legitimacy of these hypotheses, particularly when they are connected to a cross section structure, which is inalienably a discrete one. The improvement of nanoscale continuum speculations that incorporate continuum mechanics hypotheses with the nanoscale atomic structure has stirred considerably more intrigue. These displaying methods are alluded to as "nanoscale mechanics" or "sub-atomic auxiliary mechanics" in the writing, and they interface the interatomic possibilities of nuclear structure to the continuum level of materials. Two broadly utilized procedures of Nano continuum demonstrating are the semi continuum and proportional continuum techniques [17]. The semi continuum technique, presented by Tadmor et al. [18], gives a connection between the misshapenness of a continuum with that of its precious stone grid by utilizing the traditional Cauchy- Born run the show. The equal continuum strategy, created by Odegard et al. [19], joins the computational science to strong mechanics by likening the sub-atomic potential vitality of a nanostructure with the strain vitality of its delegate continuum components. A general photo of the explanatory continuum techniques utilized and grew so far to foresee the versatile modulus of SWCNTs is abridged. Numerical continuum mechanics are in light of the FEMs. The interests for changes in the demonstrating systems and for the advancement of quicker techniques to process the mechanical properties of CNTs have inspired scientists to utilize the FEMs. Various types of limited components, including poles, brackets, shafts, and springs, have been utilized to demonstrate the carbon-carbon (C-C) interface in CNTs. Chang and Gao [20] 
expressed that the $\mathrm{C}-\mathrm{C}$ interface dependably stays straight paying little respect to the heap connected and along these lines spring components are liked to display this connection. Nasdala and Ernst [21] found that the standard limited components, for example, brackets, bars, or shells, are not extremely reasonable for displaying the twisting edge in nanotubes. General footages of the numerical continuum mechanics approaches utilized as a part of foreseeing the versatile properties of SWCNTs is introduced. General footages of the utilized techniques by various scientists are to anticipate the versatile modulus of SWCNTs and the patterns of results as far as three primary parameters of range of morphology.

The errors between the outcomes are because of the distinctive possibilities utilized, diverse parameters utilized as a part of a similar potential, and distinctive tube thicknesses. Besides, contrasting the current information for the versatile modulus of CNTs, which is seen that there are likewise a few irregularities in the pattern of variety in the flexible modulus as far as nanotube range. Cornwell, Wille [24], Yao, and Lordi [29] revealed the diminishing utilization of atomistic displaying, while Zhang et al. [45] and Gao and $\mathrm{Li}$ [60] detailed the same in rolling a graphene sheet into a CNT. Natsuki et al. [46] additionally report that a CNT more much of the time is supplanted with a ceaseless strong barrel. As opposed to the couple of examinations announcing a lessening in Young's modulus with developing tube distance across, the larger part of specialists have discovered an expanding conduct of the modulus. The supporter of the last discoveries is the way that the flexible modulus of SWCNTs approaches that of a graphene and the promoter of the last discoveries is the way that the flexible modulus of SWCNTs approaches that of a graphene sheet at expansive nanotube distances. The purpose behind this marvel is the high ebb and flow of CNTs with a little measurement, which brings about a more prominent mutilation of $\mathrm{C}-\mathrm{C}$ bonds. As the nanotube width builds, the impact of ebb and flow reduces bit-by-bit [45, 62-64, 68]. Despite the technique connected, it can be seen that every one of the irregularities fundamentally show up at little nanotube distances across, and in all cases, the versatile modulus of SWCNTs approaches that of a graphene sheet everywhere nanotube measurements. The outcomes acquired by Natsuki et al. [46] and GAO and Li [60] are the main ones as per which the modulus approaches zero when the tube breadth watches out for endlessness. Then again, the contrasts between the outcomes detailed can be ascribed to the utilization of various suppositions, models, compel field parameters, and interatomic possibilities and distinctive meanings of the versatile modulus. Thusly, the investigation of the mechanical properties of CNTs is a progressing procedure yet. Another critical issue in displaying nanotubes is the meaning of their equal continuum thickness. Most specialists [22, 26, 29, 31, 42] consider this amount as the interlunar separating of graphene sheets $(0.34 \mathrm{~nm})$, while some others, as Odegard et al. [19] and Yakobson et al. [27], acquired 0.68 and $0.066 \mathrm{~nm}$, individually, for this parameter. The ostensible incentive for the hub Young's modulus was observed to be around $1 \mathrm{TPa}$ and for Poisson's proportion 0.20 to 0.30 . A few analysts have endeavoured to foresee the Young's modulus of CNTs from the modulus of graphene sheets. They expect that the modulus of a graphene sheet is equivalent to that of a roundly moved sheet speaking to a SWCNT. This technique does not enable one to catch the impact of auxiliary unwinding [79]. Dialog. The places of various atomistic and continuum displaying strategies, as far as both time and length scales, are appeared. Of every single distinctive procedure, the comparable continuum approach created by Odegard et al. [19] and the basic mechanics approach created by Li and Chou [63] have been accepting more consideration because of the nearness of the two-reproduction methodology to the regular conduct of SWCNTs. The principle ideas of these strategies are quickly outlined underneath. Odegard et al. $[19,81]$ was the first to propose 
the possibility of a successful fibre and supplant the $\mathrm{C}-\mathrm{C}$ bond with equal continuum bracket components; nonetheless, they did not consider the torsion of $\mathrm{C}-\mathrm{C}$ bonds. The techniques give a connection between the computational science used to foresee the sub-atomic properties of materials and the strong mechanics, depicting the perceptible mechanical conduct of materials based on their mass properties. Their demonstrating system involves two phases. To begin with, the discrete sub-atomic structure is supplanted with a halfway model comprising of two sorts of bracket components, one of which catches changes in the bond length and alternate portrays point varieties. It has been demonstrated that this substitution might be expert by comparing the atomic potential vitality of nanostructured materials with the mechanical strain vitality of bracket components. Second, the bracket-based model is supplanted with an identical constant barrel. The substitution is completed by likening the strain vitality of the barrel with the mechanical strain vitality of the middle of the road bracket based model. Li and Chou [63] effectively built up a continuum mechanics display for depicting the mechanical properties of nanotubes by connecting the atomic mechanics constants of power fields with the solidness parameters of casing areas. They set up a connection between's the interatomic atomic potential vitality and the strain vitality of a bar by utilizing the proportionality of energies. The creators utilized their own particular displaying method of auxiliary mechanics to separate the

In another investigation, they used the van der Waals communication and acquired the Young's modulus of MWCNTs [82]. The creators have additionally researched the tractable and compressive conduct of SWCNT-fortified composite and stress circulations at the interphase [83, 84]. In spite of the fact that they reproduced SWCNTs installed in a polymer lattice considering the interphase too, they did not supplant a SWCNT and its encompassing polymer with a comparable fibre. A few scientists built their displaying systems in light of the basic mechanics approach [65, 68, 71, 74, 77] initially created by Li and Chou [63]. The FEM displayed beforehand by Li and Chou was altered by To [71], with the impact of Poisson's proportion incorporated into deciding the Young's and shear moduli of SWCNTs. Tserpes and Papanikos [74] used a similar reproduction approach of $\mathrm{Li}$ and Chou [63] by utilizing a 3-D pillar component worked in the ANSYS business FEM bundle. Kalamkarov et al. [65] likewise utilized the demonstrating method of $\mathrm{Li}$ and Chou in the numerical piece of their examination to anticipate the Young's modulus of single-walled, twofold walled and multiwalled CNTs (MWCNTs) by utilizing the ANSYS bundle. Besides, they built up a scientific strategy in light of the asymptotic homogenization, on the system of a tube-shaped shell and contrasted the outcomes acquired, and those found by a limited component investigation. A few scientists utilized the comparable continuum technique or the auxiliary mechanics approach in researching the mechanical properties of CNT-fortified polymers and affirmed the productivity of these strategies. The primary deficiency of the comparable continuum approach is the concentrated calculations and muddled examinations required. In the proportionate continuum approach, the connection between is the auxiliary and atomic mechanics is found by likening the sub-atomic potential vitality of the entire sub-atomic structure with the mechanical strain vitality of all support components. Nevertheless, the basic mechanics approach builds up a relationship between is the interatomic atomic potential energies and the strain energies of each single bar speaking to the C-C bonds by utilizing the comparability of energies. Writing Survey of the Mechanical Properties of CNT Composites The hypothetical examinations on foreseeing the mechanical properties of SWCNT-fortified polymers can be isolated into three gatherings: atomistic demonstrating, continuum displaying (systematic and numerical) and 
multiscale techniques. A general photo of the distinctive strategies utilized by different scientists to acquire the Young's modulus of SWCNT/polymer.

In view of blend of Chan-Wang, Hsiao- Daneil, Chamis, and Christensen- Waals. Mori- Tanaka, the limit component strategy, the creators regarded the interphase as both hard and delicate materials, and the versatile modulus of the interphase was thought to be 10 and 0.3 times as expensive as the framework modulus, while the thickness of the interphase was thought to be equivalent to the mean span of nanotube. Self-steady, Parametric thinks about on the impact of interphases with a versatile modulus going from one tenth of that of the framework to 10 times the network modulus and with a thickness from a large portion of the CNT span to four times the range were performed. Using the atomistic displaying for composites to ponder their neighbourhood conduct at the nanoscale is unavoidable. In any case, as expressed previously, the sub-atomic unique reproduction is constrained too little length and brief time scales. For example, all aftereffects of atomic re-enactments for CNT composites are restricted to models containing one $\mathrm{CNT}$ in a polymer grid. The portrayal of a CNT composite requires just the learning of its worldwide reactions, for example, the dislodging and stress fields at the limits of an agent volume component. Consequently, the continuum mechanics methodologies might be satisfactory and adequate in demonstrating CNT composites in such manner. Alongside these strategies, the favoured approach for the reproductions of CNT composites ought to be a multiscale one, where the MD and continuum mechanics are incorporated in a registering domain sufficiently gritty to represent the material science at the nanoscale, yet sufficiently effective to deal with CNT composites at bigger length scales [85].

The multiscale techniques, which have been effectively utilized by various analysts, can examine the conduct of materials from the nano-to macro scale. Hole Analysis As observed, the dominant part of studies consider an ideal holding in the interphase locale, however there are thinks about where the interphase is dealt with as nonbonded. A few examinations have essentially entered the impact of nonbonded interphase area by utilizing a firmness decrease productivity factor [66, 86, 97], while in others the interphase locale is portrayed by Van der Waals nonbonded cooperation $[63,83,84,116,117]$. A predetermined number of examinations are devoted to the waviness of CNTs in a polymer $[90,92,101,109$, and 118]. In all the previously mentioned investigations, a CNT was supplanted with a strong continuum fibre, and the impact of solidness decrease was analysed either diagnostically or numerically. To the best of our insight, no investigation has been performed on the waviness of CNTs in composites within the sight of Van der Waals interphase districts. One of the primary downsides of most investigations on foreseeing the mechanical properties of CNT composites is the immediate utilization of the micromechanics conditions reasonable for stringy composites $[67,86,90,92,96,97,101,107]$. In particular, they supplant the cross section structure of a CNT with a strong fibre. It has been demonstrated that the immediate utilization of micromechanics conditions to CNT composites will prompt wrong outcomes [81, 107, 112,114, 116, 117, and 119]. In addition, the primary presumption of micromechanics conditions is a ceaseless strong medium, which is not substantial for the grid structure of CNTs. Odegard et al. [19,81] set forth the possibility of a proportionate fibre, which is proper for micromechanics conditions when the heap exchange from the lattice to CNTs is enhanced by poly-m-phenylenevinylene (PmPV) oligomers. Some different examiners utilized their own particular strategies in the examination [67, 109, 113, and 115]. 


\section{Conclusions and Recommendations}

All examinations directed moved toward the forecast of mechanical properties of CNT composites as a deterministic issue. Spanos and Kontsos are the main creators who utilized the stochastic approach for this reason [115-121]. Conclusions although various investigations have been directed on the mechanical properties of CNT composites; a few parts of the issue still must be tended to. More consideration ought to be given to the interphase area between a CNT and its encompassing polymer and to the issue of pressure exchange from the network to CNTs. The waviness of installed CNTs must be viewed as more precisely, particularly within the sight of Van der Waals nonbonded connections in the interphase area. An immediate utilization of micromechanics conditions at the nanoscale will prompt dishonourable outcomes, since these conditions cannot catch the impact of distinction between the nano-and microscales. Preceding the work of micromechanics conditions, a reasonable procedure (as if the equal continuum mechanics created by Odegard et al. [19] ought to be utilized to change over CNTs and the interphase locale at the nanoscale into a proportionate fibre at the microscale. Since the scattering and appropriation of CNTs in a polymer framework is not deterministic, the usage of the stochastic approach is unavoidable to acquire outcomes that are more precise.

\section{References}

[1] Cha, J., Jin, S., Shim, J. H., Park, C. S., Ryu, H. J. and Hong, S. H.: Functionalization of carbon nanotubes for fabrication of CNT/epoxy nanocomposites, Materials \& Design, 5, 95, 1-8, 2016.

[2] Ramanathan, M., Shanov, V., Kumta, P. N.: Carbon Nanotube-Based Impedimetric Biosensors for Bone Marker Detection, Mitali Patil Department of Bioengineering, Swanson School of Engineering, University of Pittsburgh, Pittsburgh, Pennsylvania, USA, Advances in Materials Science for Environmental and Energy Technologies IV: Ceramic Transactions, 253, 187, 2015.

[3] Pradhan, S., Pandey, P., Mohanty, S. and Nayak, S. K.: Insight on the Chemistry of Epoxy and Its Curing for Coating Applications: A Detailed Investigation and Future Perspectives. PolymerPlastics Technology and Engineering, 55, 8, 862-77, 2016.

[4] H“unnekens, B., Peters, F., Avramidis, G., Krause, A., Militz, H. and Vi“ol, W.: Plasma treatment of wood-polymer composites: A comparison of three different discharge types and their effect on surface properties, Journal of Applied Polymer Science, 133, 18, 2016.

[5] Bonduel, D., Kchit, N. and Claes, M.: Use of carbon nanotubes in structural composites, Smart Intelligent Aircraft Structures (SARISTU), Springer International Publishing, 755-762, 2016.

[6] Chen, Y., Zhang, H. B., Yang, Y., Wang, M., Cao, A. and Yu, Z. Z.: High-Performance Epoxy Nanocomposites Reinforced with Three-Dimensional Carbon Nanotube Sponge for Electromagnetic Interference Shielding, Advanced Functional Materials, 26, 3, 447-55, 2016.

[7] Islam, M. S., Deng, Y., Tong, L., Faisal, S. N., Roy, A. K., Minett, A. I. and Gomes, V. G.: Grafting carbon nanotubes directly onto carbon fibers for superior mechanical stability: Towards next generation aerospace composites and energy storage applications, Carbon, 96, 701-10, 2016.

[8] Tornabene, F., Fantuzzi, N., Bacciocchi, M. and Viola, E.: Effect of agglomeration on the natural frequencies of functionally graded carbon nanotube-reinforced laminated composite doubly-curved shells, Composites Part B: Engineering, 89, 187- 218, 2016.

[9] G'omez-del R'10, T., Salazar, A., Pearson, R. A. and Rodr'1guez, J.: Fracture behaviour of epoxy nanocomposites modified with triblock copolymers and carbon nanotubes, Composites Part B: Engineering, 87, 343-9, 2016.

[10] Fujigaya, T., Saegusa, Y., Momota, S., Uda, N. and Nakashima, N.: Interfacial engineering of epoxy/carbon nanotubes using reactive glue for effective reinforcement of the composite, Polymer Journal, 48, 2, 183-8, 2016. 
[11] Zhou, H. W., Mishnaevsky, L., Yi, H. Y., Liu, Y. Q., Hu, X., Warrier, A. and Dai, G. M.: Carbon fiber/carbon nanotube reinforced hierarchical composites: Effect of CNT distribution on shearing strength, Composites Part B: Engineering, 88, 201-11, 2016.

[12] Randjbaran, E., Zahari, R., Abdul Jalil, N. A. and Majid, D. L.: Hybrid composite laminates reinforced with kevlar/carbon/glass woven fabrics for ballistic impact testing, The Scientific World Journal, 2014.

[13] Randjbaran, E., Zahari, R., Majid, D. L., Jalil, N. A., Vaghei, R. andAhmadi, R.; The effects of stacking sequence layers of six layers composite materials in ballistic energy absorption, International Journal of Material Science Innovations, 1, 6, 293-305, 2013.

[14] Randjbaran, E., Zahari, R., Majid, D. L., Jalil, N. A., Vaghei, R. and Ahmadi, R.: The effects of stacking sequence layers of hybrid composite materials inenergy absorption under the high velocity ballistic impact conditions: an experimental investigation, Journal of Material Sciences \& Engineering, 2013.

[15] Randjbaran, E., Zahari, R., Majid, D. L., Jalil, N. A., Vaghei, R. and Ahmadi, R.: Effects of Stacking Sequence on Compression Response Testing of Carbon Fibre and Hybrids: FibrousGlass/Carbon/Kevlar/Epoxy Composite Plates, MATRIX Academic International Online Journal of Engineering and Technology, 2, 1, 13-7, 2013.

[16] Randjbaran, E., Zahari, R., Majid, D. L., Jalil, N. A., Vaghei, R. and Ahmadi, R.: Experimental Study of the Influence of Stacking Order of the Fibrous Layers on Laminated Hybrid Composite Plates Subjected to Compression Loading, Journal of Science and Engineering, 4, 1, 01-8, 2014.

[17] Randjbaran, E., Zahari, R., Vaghei, R. and Karamizadeh, F.: A Review Paper on Comparison of Numerical Techniques for Finding Approximate Solutions to Boundary Value Problems on PostBuckling in Functionally Graded Materials, Trends Journal of Sciences Research, 1, 1, 1-6, 2015.

[18] Randjbaran, E., Zahari, R. and Vaghei, R.: Scanning Electron Microscopy Interpretation In Carbon Nanotubes Composite Materials After Postbuckling - Review Paper, MATRIX Academic International Online Journal of Engineering and Technology, 2, 2, 1-6, 2014.

[19] Randjbaran, E., Zahari, R. and Vaghei, R.: Computing Simulation of Postbuckling in Functionally Graded Materials - A Review, Indonesian Journal of Electrical Engineering and Computer Science, 12, 12, 8344-8, 2014.

[20] Randjbaran, E., Zahari, R., Majid D. L., Sultan, M. T. H. and Mazlan, N.: Effects of Carbon Nanotube on Mechanical Properties of Composite plates - A Review Paper, MATRIX Academic International Online Journal of Engineering and Technology, 3, 2, 1-8, 2015. http://maioj.org/pub.aspx?PaperId=101503.

[21] Reddy, P. R., Reddy, T. S., Srikanth, I., Madhu, V., Gogia, A. K. and Rao, K. V.: Effect of viscoelastic behaviour of glass laminates on their energy absorption subjected to high velocity impact, Materials \& Design, 98, 272-9, 2016.

[22] Saba, N., Paridah, M. T., Abdan, K. and Ibrahim, N. A.: Dynamic mechanical properties of oil palm nano filler/kenaf/epoxy hybrid nanocomposites, Construction and Building Materials, 124, 133-8, 2016.

[23] Ostovan, F., Matori, K. A., Toozandehjani M., Oskoueian, A., Yusoff, H. M., Yunus, R., Ariff, A. H., Quah, H. J. and Lim, W. F.: Effects of CNTs content and milling time on mechanical behavior of MWCNT-reinforced aluminum nanocomposites, Materials Chemistry and Physics, 166, 160-6, 2015.

[24] Shabaneh, A., Girei, S., Arasu, P., Mahdi, M., Rashid, S., Paiman, S. and Yaacob, M.: Dynamic response of tapered optical multimode fiber coated with carbon nanotubes for ethanol sensing application, Sensors, 15, 5, 10452-64, 2015.

[25] Ramli, N. I., Rashid, S. A., Sulaiman, Y., Mamat, M. S., Zobir, S. A., Krishnan, S.: Physicochemical and electrochemical properties of carbon nanotube/graphitenanofiber hybrid nanocomposites for supercapacitor, Journal of Power Sources, 328, 195-202, 2016. 
[26] Ghaemi, F., Yunus, R., Salleh, M. A., Rashid, S. A., Ahmadian, A. and Lim, H. N.: Effects of the surface modification of carbon fiber by growing different types of carbon nanomaterials on the mechanical and thermal properties of polypropylene, RSC Advances, 5, 36, 28822-31, 2015.

[27] Shojaei, T. R., Salleh, M. A., Sijam, K., Rahim, R. A., Mohsenifar, A., Safarnejad, R. and Tabatabaei, M.: Fluorometric immunoassay for detecting the plant virus Citrus tristeza using carbon nanoparticles acting as quenchers and antibodies labeled with CdTe quantum dots, Microchimica Acta, 1-1, 2016.

[28] Lomicka, C. W., Thomas, J. A., LaBarre, E. D., Trexler, M. M, Merkle, a. C.: Improving ballistic fiber strength: insights from experiment and simulation, Dynamic Behavior of Materials, Springer International Publishing, 1, 187-193, 2014.

[29] Randjbaran, E., Zahari, R., Majid, D. L., Sultan, M. T. H. and Mazlan, N.:Effects of Sloped Armour in Ballistic Impact Resistance - A Review Paper, MATRIX Academic International Online Journal of Engineering and Technology, 4, 2, 2016. http://maioj.org/data/documents/oct2016/101603.pdf.

[30] Shang, Y., Hua, C., Xu, W., Hu, X., Wang, Y., Zhou, Y., Zhang, Y., Li, X. and Cao, A.: MeterLong Spiral Carbon Nanotube Fibers Show Ultrauniformity and Flexibility, Nano letters, 16, 3, 1768-75, 2016.

[31] Wu, X., Morimoto, T., Mukai, K., Asaka, K. and Okazaki, T.: Relationship between Mechanical and Electrical Properties of Continuous Polymer-Free Carbon Nanotube Fibers by Wet-Spinning Method and Nanotube-Length Estimated by FarInfrared Spectroscopy, J. Phys. Chem. C, 120, 36, 20419-20427, 2016

[32] Liu, P., Fan, Z., Mikhalchan, A., Tran, T. Q., Jewell, D., Duong, H. M. and Marconnet, A. M.: Continuous Carbon Nanotube-Based Fibers and Films for Applications Requiring Enhanced Heat Dissipation, ACS Applied Materials \& Interfaces, 8, 27, 17461-71, 2016.

[33] Xu, W., Chen, Y., Zhan, H. and Wang, J. N.: High-Strength Carbon Nanotube Film from Improving Alignment and Densification, Nano letters, 16, 2, 946-52, 2016.

[34] Zare, M., Rayegan-Shirazi, A., Rezaei, S., Sadat, S. A., Baneshi, M. M. and Randjbaran, E.: Effects of Polychlorinated biphenyls compounds on the number of bacteria in the rhizosphere of sorghum and Onobrychis sativa, Advances in Bioresearch, 7, 3, 2016.

[35] Mirri, F., Orloff, N. D., Forster, A. M., Ashkar, R., Headrick, R. J., Bengio, E. A., Long, C. J., Choi, A., Luo, Y., Hight Walker, A. R. and Butler, P.: Lightweight, flexible, high-performance carbon nanotube cables made by scalable flow coating, ACS applied materials \& interfaces, 8, 7, 4903-10, 2016.

[36] Davaa, E., Safari, M., Randjbaran, E. and Randjbaran, S.: The Factors That Influence Customer Satisfaction Level in the Mongolian Banking Industry, Journal of Insurance and Financial Management, 1, 3, 2016.

[37] O'Connor, I., Hayden, H., Coleman, J. N. and Gun'ko, Y. K.: High-Strength, High-Toughness Composite Fibers by Swelling Kevlar in Nanotube Suspensions, Small, 5, 4, 466-9, 2009.

[38] Govarthanam, K. K., Anand, S. C. and Rajendran, S.: 7 Technical textiles for knife and slash resistance, Handbook of Technical Textiles: Technical Textile Applications, 2, 193, 2016.

[39] Dwivedi, A. K., Dalzell, M. W., Fossey, S. A., Slusarski, K. A., Long, L. R. and Wetzel, E. D.: Low velocity ballistic behavior of continuous filament knit aramid, International Journal of Impact Engineering, 96, 23-34, 2016.

[40] Yang, D. and Chen, X.: Multi-layer pattern creation for seamless front female body armor panel using angle-interlock woven fabrics, Textile Research Journal, 0040517516631315, 2016.

[41] Lomicka, C. W., Thomas, J. A., LaBarre, E. D., Trexler, M. M. and Merkle, A. C.: Improving ballistic fiber strength: insights from experiment and simulation, Dynamic Behavior of Materials, Springer International Publishing 1, 187-193, 2014.

[42] Sockalingam, S., Chowdhury, S. C., Gillespie, J. W. and Keefe, M.: Recent advances in modeling and experiments of Kevlar ballistic fibrils, fibers, yarns and flexible woven textile fabrics-a review, Textile Research Journal, 004051751664603, 2016. 
[43] O'Connor, I., Hayden, H., Coleman, J. N. and Gun'ko, Y. K.: High-Strength, High-Toughness Composite Fibers by Swelling Kevlar in Nanotube Suspensions, Small, 5, 4, 466-9, 2009.

[44] Zheng, J., Duan, X., Lin, H., Gu, Z., Fang, H., Li, J. and Yuan, Y.: Silver nanoparticles confined in carbon nanotubes: on the understanding of the confinement effect and promotional catalysis for the selective hydrogenation of dimethyl oxalate, Nanoscale, 8, 11, 5959-67, 2016.

[45] Haft, M., Gr"onke, M., Gellesch, M., Wurmehl, S., B“uchner, B., Mertig, M. and Hampel, S.: Tailored nanoparticles and wires of $\mathrm{Sn}, \mathrm{Ge}$ and $\mathrm{Pb}$ inside carbon nanotubes, Carbon, 101, 352-60, 2016.

[46] Gun'ko, V. M. and Do, D. D.: Characterisation of pore structure of carbon adsorbents using regularisation procedure, Colloids and Surfaces A: Physicochemical and Engineering Aspects, 193, $1,71-83,2001$.

[47] Gun'ko, V. M. and Mikhalovsky, S. V.: Evaluation of slitlike porosity of carbon adsorbents, Carbon, 42, 4, 843-9, 2004.

[48] Jiang, L. Y., Huang, Y., Jiang, H., Ravichandran, G., Gao, H., Hwang, K. C. and Liu, B.: A cohesive law for carbon nanotube/polymer interfaces based on the van der Waals force, Journal of the Mechanics and Physics of Solids, 54, 11, 2436-52, 2006.

[49] Wong, M., Paramsothy, M., Xu, X. J., Ren, Y., Li, S. and Liao, K.: Physical interactions at carbon nanotube-polymer interface, Polymer, 44, 25, 7757-64, 2003.

[50] Liao, K. and Li, S.: Interfacial characteristics of a carbon nanotube-polystyrene composite system, Applied Physics Letters, 79, 25, 4225-7, 2001.

[51] Veedu, V. P., Cao, A., Li, X., Ma, K., Soldano, C., Kar, S., Ajayan, P.M. and Ghasemi-Nejhad, M. N.: Multifunctional composites using reinforced laminae with carbon-nanotube forests, Nature materials, 5, 6, 457-62, 2006.

[52] Wang, Y., Colas, G. and Filleter, T.: Improvements in the mechanical properties of carbon nanotube fibers through graphene oxide interlocking, Carbon, 98, 291-9, 2016.

[53] Koizumi, R., Hart, A. H., Brunetto, G., Bhowmick, S., Owuor, P. S., Hamel, J. T., Gentles, A. X., Ozden, S., Lou, J., Vajtai, R. and Asif, S. S.: Mechano-chemical stabilization of three-dimensional carbon nanotube aggregates, Carbon, 110, 27-33, 2016.

[54] Chowdhury, S. C. and Okabe, T.: Computer simulation of carbon nanotube pullout from polymer by the molecular dynamics method, Composites Part A: Applied Science and Manufacturing, 38, 3, 747-54, 2007.

[55] Li, Y., Liu, Y., Peng, X., Yan, C., Liu, S. and Hu, N.: Pull-out simulations on interfacial properties of carbon nanotube-reinforced polymer nanocomposites. Computational Materials Science, 50, 6, 1854-60, 2011.

[56] Wagner, H. D. and Vaia, R. A.: Nanocomposites: issues at the interface, Materials Today, 7, 11, 38-42, 2004.

[57] Wagner, H. D., Ajayan, P. M. and Schulte, K.: Nanocomposite toughness from a pull-out mechanism, Composites Science and Technology, 83, 27-31, 2013.

[58] Esawi, A. M., Morsi, K., Sayed, A., Taher, M. and Lanka, S.: Effect of carbon nanotube (CNT) content on the mechanical properties of CNT-reinforced aluminium composites, Composites Science and Technology, 70, 16, 2237-41, 2010.

[59] He, X. Q., Kitipornchai, S. and Liew, K. M.: Buckling analysis of multi-walled carbon nanotubes: a continuum model accounting for van der Waals interaction, Journal of the Mechanics and Physics of Solids, 53, 2, 303-26, 2005.

[60] Jiang, L. Y., Huang, Y., Jiang, H., Ravichandran, G., Gao, H., Hwang, K. C. and Liu, B.: A cohesive law for carbon nanotube/polymer interfaces based on the van der Waals force, Journal of the Mechanics and Physics of Solids, 54, 11,2436-52, 2006.

[61] Tan, H., Jiang, L. Y., Huang, Y., Liu, B. and Hwang, K. C.: The effect of van der Waals-based interface cohesive law on carbon nanotube-reinforced composite materials, Composites Science and Technology, 67, 14, 2941-6, 2007. 
[62] Liu, X., Yang, Q. S., He, X. Q. and Liew, K. M.: Cohesive laws for van der Waals interactions of super carbon nanotube/polymer composites, Mechanics Research Communications, 72, 33-40, 2016.

[63] Nagataki, A., Takei, K., Arie, T. and Akita, S.: Carbon nanotube mechanical resonator in potential well induced by van der Waals interaction with graphene, Applied Physics Express, 8, 8, 085101, 2015.

[64] Zhang, X., Zhou, W. X., Chen, X. K., Liu, Y. Y. and Chen, K. Q.: Significant decrease in thermal conductivity of multi-walled carbon nanotube induced by interwall van der Waals interactions, Physics Letters A, 380, 21, 1861-4, 2016.

[65] Chernozatonskii, L. A., Artyukh, A. A., Demin, V. A. and Katz, E. A.: Bucky-corn: van der Waals composite of carbon nanotube coated by fullerenes, Molecular Physics, 114, 9, 92-101, 2016.

[66] Perebeinos, V. and Tersoff, J.: Wetting transition for carbon nanotube arrays under metal contacts, Physical review letters, 114, 8, 085501, 2015.

[67] Tornabene, F., Fantuzzi, N., Bacciocchi, M. and Viola, E.: Effect of agglomeration on the natural frequencies of functionally graded carbon nanotube-reinforced laminated composite doubly-curved shells, Composites Part B: Engineering, 89, 187-218, 2016.

[68] Kumar, A. A., Sundaram, R.: Cure cycle optimization for the resin infusion technique using carbon nanotube additives, Carbon, 96, 1043-52, 2016.

[69] Kamarian, S., Salim, M., Dimitri, R. and Tornabene, F.: Free vibration analysis of conical shells reinforced with agglomerated Carbon Nanotubes, International Journal of Mechanical Sciences, 108, 157-65, 2016.

[70] Rathore, D. K., Singh, B. P., Mohanty, S. C., Prusty, R. K. and Ray, B. C.: Temperature dependent reinforcement efficiency of carbon nanotube in polymer composite, Composites Communications, 1, 29-32, 2016.

[71] Bautista-Quijano, J. R., P“otschke, P., Br"unig, H. and Heinrich, G.:Strain sensing, electrical and mechanical properties of polycarbonate/multiwall carbon nanotube monofilament fibers fabricated by melt spinning, Polymer, 82, 181-9, 2016.

[72] Herceg, T. M., Abidin, M. S., Greenhalgh, E. S., Shaffer, M. S., Bismarck, A.; Thermosetting hierarchical composites with high carbon nanotube loadings: En route to high performance, Composites Science and Technology, 127, 134-41, 2016.

[73] Wang, J., Bahk, Y. K., Chen, S. C., Pui, D. Y.: Characteristics of airborne fractal-like agglomerates of carbon nanotubes, Carbon, 93, 441-50, 2015.

[74] Moghadam, A. D., Omrani, E., Menezes, P. L., Rohatgi, P. K.: Mechanical and tribological properties of self-lubricating metal matrix nanocomposites reinforced by carbon nanotubes (CNTs) and graphene-a review, Composites Part B: Engineering, 77, 402-20, 2015.

[75] Chen, S. J., Qiu, C. Y., Korayem, A. H., Barati, M. R.and Duan, W. H.: Agglomeration process of surfactant-dispersed carbon nanotubes in unstable dispersion: A two-stage agglomeration model and experimental evidence, Powder Technology, 301, 412-20, 2016.

[76] Romanov, V. S., Lomov, S. V., Verpoest, I., Gorbatikh, L.: Stress magnification due to carbon nanotube agglomeration in composites, Composite Structures, 133, 246-56, 2015.

[77] Balasubramanian, K., Burghard, M.: Chemically functionalized carbon nanotubes, Small, 1, 2, 180-92, 2005.

[78] Wong, S. S., Joselevich, E., Woolley, A. T., Cheung, C. L., Lieber, C. M.: Covalently functionalized nanotubes as nanometre-sized probes in chemistry and biology, Nature, 394, 6688, 52-5, 1998.

[79] Banerjee, S., Hemraj-Benny, T., Wong, S. S.: Covalent surface chemistry of single-walled carbon nanotubes, Advanced Materials, 17, 1, 17-29, 2005.

[80] Bianco, A., Kostarelos, K., Prato, M.: Applications of carbon nanotubes in drug delivery, Current opinion in chemical biology, 9, 6, 674-9, 2005. 
[81] Spitalsky, Z., Tasis, D., Papagelis, K. and Galiotis, C.: Carbon nanotube- polymer composites: chemistry, processing, mechanical and electrical properties, Progress in polymer science, 35, 3, 357-401, 2010.

[82] Salvetat, J. P., Bonard, J. M., Thomson, N. H., Kulik, A. J., Forro, L.,Benoit, W. and Zuppiroli, L.: Mechanical properties of carbon nanotubes, Applied Physics A, 69, 3, 255-60, 1999.

[83] Wei, B. Q., Vajtai, R. and Ajayan, P. M.: Reliability and current carrying capacity of carbon nanotubes, Applied Physics Letters, 79, 8, 1172, 2001.

[84] Li, Q. W., Li, Y., Zhang, X. F., Chikkannanavar, S. B., Zhao, Y. H., Dangelewicz, A. M., Zheng, L. X., Doorn S. K., Jia, Q. X., Peterson, D. E. and Arendt, P. N.: Structure-dependent electrical properties of carbon nanotube fibers. Advanced Materials, 19, 20, 3358-63, 2007.

[85] Dumitrica, T., Landis, C. M. and Yakobson, B. I.: Curvature-induced polarization in carbon nanoshells, Chemical physics letters, 360, 1, 182-8, 2002.

[86] Zhang, H. W., Wang, J. B. and Guo, X.: Predicting the elastic properties of single-walled carbon nanotubes, Journal of the Mechanics and Physics of Solids, 53, 9, 1929-50, 2005.

[87] Banhart, F.: Interactions between metals and carbon nanotubes: at the interface between old and new materials, Nanoscale, 1, 2, 201-13, 2009.

[88] Jakubinek, M. B., Ashrafi, B., Zhang, Y., Martinez-Rubi, Y., Kingston, C. T., Johnston, A. and Simard, B.: Single-walled carbon nanotube-epoxy composites for structural and conductive aerospace adhesives, Composites Part B: Engineering, 69, 87-93, 2015.

[89] Papadopoulos, A., Gkikas, G., Paipetis, A. S., Barkoula, N. M.: Effect of CNTs addition on the erosive wear response of epoxy resin and carbon fibre composites, Composites Part A: Applied Science and Manufacturing, 84, 299-307, 2016.

[90] Fujigaya, T., Saegusa, Y., Momota, S., Uda, N. and Nakashima, N.: Interfacial engineering of epoxy/carbon nanotubes using reactive glue for effective reinforcement of the composite, Polymer Journal, 48, 2, 183-8, 2016.

[91] Sun, Y., Lu, J., Ai, C., Wen, D. and Bai, X.: Multilevel resistive switching and nonvolatile memory effects in epoxy methacrylate resin and carbon nanotube composite films, Organic Electronics, 32, 7-14, 2016.

[92] Ling, Y., Li, W., Wang, B., Gan, W., Zhu, C., Brady, M. A. and Wang, C.: Epoxy resin reinforced with nanothin polydopamine-coated carbon nanotubes: a study of the interfacial polymer layer thickness, RSC Advances, 6, 37, 31037-45, 2016.

[93] Mei, H., Zhang, S., Chen, H., Zhou, H., Zhai, X. and Cheng, L.: Interfacial modification and enhancement of toughening mechanisms in epoxy composites with CNTs grafted on carbon fibers, Composites Science and Technology, 134, 89-95, 2016.

[94] Wu, J., Chen, J., Zhao, Y., Liu, W. and Zhang, W.: Effect of electrophoretic condition on the electromagnetic interference shielding performance of reduced graphene oxide-carbon fiber/epoxy resin composites, Composites Part B: Engineering, 105, 167-75, 2016.

[95] Umer, R., Li, Y., Dong, Y., Haroosh, H. J. and Liao, K.: The effect of graphene oxide (GO) nanoparticles on the processing of epoxy/glass fiber composites using resin infusion, The International Journal of Advanced Manufacturing Technology, 81, 9-12, 2183-92, 2015.

[96] Schlagenhauf, L., Buerki-Thurnherr, T., Kuo, Y. Y., Wichser, A., Nuesch,F., Wick, P. and Wang, J.: Carbon Nanotubes Released from an Epoxy-Based Nanocomposite: Quantification and Particle Toxicity, Environmental Science \& Technology, 49, 17, 10616-23, 2015.

[97] Rafique, I., Kausar, A., Anwar, Z. and Muhammad, B.: Exploration of Epoxy Resins, Hardening Systems, and Epoxy/Carbon Nanotube Composite Designed for High Performance Materials: A Review, Polymer-Plastics Technology and Engineering, 55, 3, 312-33, 2016.

[98] Schlagenhauf, L., Kuo, Y. Y., Bahk, Y. K., N"uesch, F. and Wang, J.: Decomposition and particle release of a carbon nanotube/epoxy nanocomposite at elevated temperatures, Journal of Nanoparticle Research, 17, 11, 1-11, 2015. 
[99] Gong, L. X., Zhao, L., Tang, L. C., Liu, H. Y. and Mai, Y. W.: Balanced electrical, thermal and mechanical properties of epoxy composites filled with chemically reduced graphene oxide and rubber nanoparticles, Composites Science and Technology, 121, 104-14, 2015.

[100] Pathak, A. K., Borah, M., Gupta, A., Yokozeki, T. and Dhakate, S. R.: Improved mechanical properties of carbon fiber/graphene oxide-epoxy hybrid composites, Composites Science and Technology, 135, 28-38, 2016.

[101] Wang, J., Zhao, Y., Ma, F. X., Wang, K., Wang, F. B. and Xia, X. H.: Synthesis of a hydrophilic poly-L-lysine/graphene hybrid through multiple noncovalent interactions for biosensors, Journal of Materials Chemistry B, 1, 10, 1406-13, 2013.

[102] Tallury, S. S. and Pasquinelli, M. A.: Molecular dynamics simulations of polymers with stiff backbones interacting with single-walled carbon nanotubes, The Journal of Physical Chemistry B, 114, 2, 9349-55, 2010.

[103] Pan, B. and Xing, B.: Adsorption mechanisms of organic chemicals on carbon nanotubes, Environmental Science \& Technology, 42, 24, 9005-13, 2008.

[104] Xu, Z., Wei, C., Gong, Y., Chen, Z., Yang, D., Su, H. and Liu, T.: Efficient dispersion of carbon nanotube by synergistic effects of sisal cellulose nano-fiber and graphene oxide, Composite Interfaces, 1-5, 2016.

[105] Wang, Y. and Xu, Z.: Interaction mechanism of doxorubicin and SWCNT: protonation and diameter effects on drug loading and releasing, RSC advances, 6, 6, 314-22, 2016.

[106] Hua, Z., Qin, Q., Bai, X., Huang, X. and Zhang, Q.: An electrochemical biosensing platform based on 1-formylpyrene functionalized reduced graphene oxide for sensitive determination of phenol, RSC Advances, 6, 30, 25427-34, 2016.

[107] Wang, Y., Ren, P., Gu, X., Wen, X., Wang, Y., Guo, X., Waclawik, E. R., Zhu, H. and Zheng, Z.: Probing the mechanism of benzaldehyde reduction to chiral hydrobenzoin on the CNT surface under near-UV light irradiation, Green Chemistry, 18, 6, 1482-7, 2016.

[108] L'opez-Lorente, A. I. and Valc'arcel, M. ' : The third way in analytical nanoscience and nanotechnology: Involvement of nanotools and nanoanalytes in the same analytical process, $\operatorname{TrAC}$ Trends in Analytical Chemistry, 75, 1-9, 2016.

[109] Kazemi-Beydokhti, A., Heris, S. Z. and Jaafari, M. R.: Investigation of different methods for cisplatin loading using single-walled carbon nanotube, Chemical Engineering Research and Design, 112, 56-63, 2016.

[110] Hajibadi, H. and, Nowroozi, A.: Study on the interaction of metallocene catalysts with the surface of carbon nanotubes and its influence on the catalytic properties. Investigation of possible complex structures and the influence on structural and electronic properties, Journal of Organometallic Chemistry, 2016.

[111] Li, J. and Lee, E. C.: Functionalized multi-wall carbon nanotubes as an efficient additive for electrochemical DNA sensor, Sensors and Actuators B: Chemical, 239, 652-9, 2017.

[112] Bal, S. and Samal, S. S.: Carbon nanotube reinforced polymer composites - a state of the art, Bulletin of Materials Science, 30, 4, 379-86, 2007.

[113] Chen, Y., Zhang, H. B., Yang, Y., Wang, M., Cao, A. and Yu, Z. Z.: High-Performance Epoxy Nanocomposites Reinforced with Three-Dimensional Carbon Nanotube Sponge for Electromagnetic Interference Shielding, Advanced Functional Materials, 26, 3, 447-55, 2016.

[114] Fujigaya, T., Saegusa, Y., Momota, S., Uda, N. and Nakashima, N.: Interfacial engineering of epoxy/carbon nanotubes using reactive glue for effective reinforcement of the composite, Polymer Journal, 48, 2, 183-8, 2016.

[115] Bakhtiar, N. S., Akil, H. M., Zakaria, M. R., Kudus, M. H. and Othman, M. B.: New generation of hybrid filler for producing epoxy nanocomposites with improved mechanical properties, Materials \& Design, 91, 46-52, 2016.

[116] Ust"un, T., Eskizeybek, V. and Avci, A. ": Enhanced fatigue performances of hybrid nanoreinforced filament wound carbon/epoxy composite pipes, Composite Structures, 150, 124-31, 2016. 
[117] Kleinschmidt, A. C., Almeida, J. H., Donato, R. K., Schrekker, H. S., Marques, V. C., Corat, E. J. and Amico, S.C.: Functionalized-Carbon Nanotubes with Physisorbed Ionic Liquid as Filler for Epoxy Nanocomposites. Journal of Nanoscience and Nanotechnology, 16, 9, 9132-40, 2016.

[118] Randjbaran, E., Zahari, R., Majid, D.L., Sultan, M.T. and Mazlan, N.. Reasons of Adding Carbon Nanotubes into Composite Systems-Review Paper. "Mechanics and Mechanical Engineering", 21(3), pp.549-568 (2017).

[119] Akhilesh, M., K. Santarao, And M. V. S. Babu. "Thermal Conductivity Of CNT-Wated Nanofluids: A Review." Mechanics and Mechanical Engineering 22.1, 207-220 (2018).

[120] Barkhade T. EXTRACELLULAR BIOSYNTHESIS OF SILVER NANOPARTICLES USING FUNGUS PENICILLIUM SPECIES." International Journal of Research -GRANTHAALAYAH" 6(1), 277-283 (2018). DOI: 10.5281/Zenodo.1164148

[121] Mohammad S. Al-Ajely, Kareema M. Ziadan, Rafed. M. Al-Bader, PREPARATION AND CHARACTERIZATION OF CALCIUM FLUORIDE NANO PARTICLES FOR DENTAL APPLICATIONS." International Journal of Research -GRANTHAALAYAH” 6(1), 338-346 (2018). DOI: 10.5281/Zenodo.1167559

\footnotetext{
*Corresponding author.

E-mail address: Elias@ gmx.co.uk
} 